\title{
Factors associated with parents' attitudes to unhealthy foods and beverages
}

Simone Pettigrew,

Research Professor

School of Psychology and Speech Pathology

Curtin University

Kent St

Bentley, WA, 6102

Australia

Ph: +61 892667990

simone.pettigrew@curtin.edu.au

Michelle Jongenelis

Research Associate

School of Psychology and Speech Pathology

Curtin University

michelle.jongenelis@curtin.edu.au

Pascale Quester

Office of the Deputy Vice-Chancellor and Vice-President

University of Adelaide

Australia

pascale.quester@adelaide.edu.au

Kathy Chapman

Director, Cancer Programs Division

Cancer Council NSW

Australia

kathyc@nswcc.org.au

Caroline Miller

Director, SAHMRI Population Health research group Executive Officer

South Australian Health and Medical Research Institute

Australia

caroline.miller@sahmri.com

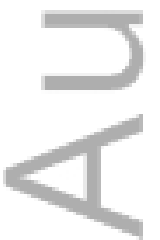

This is the author manuscript accepted for publication and has undergone full peer review but has not been through the copyediting, typesetting, pagination and proofreading process, which may lead to differences between this version and the Version of Record. Please cite this article as doi: $10.1111 /$ jpc.13148

This article is protected by copyright. All rights reserved. 


\title{
Factors associated with parents' attitudes to unhealthy foods and beverages
}

\begin{abstract}
Aim: Previous research has identified convenience, enjoyment, value for money, and perceived goodness as primary dimensions of parents' attitudes to foods and beverages. The aim of the present study was to examine the factors associated with parents' scores on each of these attitudinal dimensions to identify key issues for future interventions designed to improve parents' food provision behaviours and children's diets.
\end{abstract}

Methods: A sample of 1,302 Australian parents of children aged 8 to 14 years completed an online survey relating to their food-related beliefs. Linear regression analyses were undertaken to examine factors associated with parents' attitudes to soft drinks and energydense nutrient-poor foods.

Results: Consistent factors were identified for both energy-dense, nutrient-poor foods and soft drinks, indicating that similar approaches could be adopted in interventions for both product categories. The primary factors were social norms, child pestering, television viewing, and exposure to food advertising.

Conclusions: Food advertising represents a common link between the primary factors, indicating that it constitutes a critical component of future interventions designed to modify parents' attitudes to unhealthy food products and to reduce the frequency with which these foods are consumed by children. 


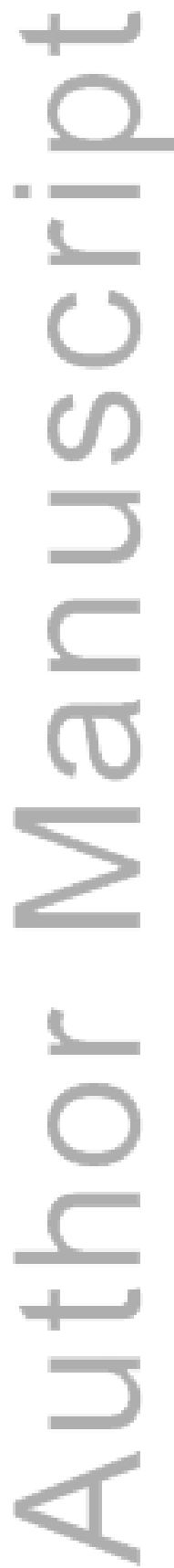

This article is protected by copyright. All rights reserved. 


\section{What is already known on this topic:}

1. Population levels of obesity are too high, especially among children.

2. Parents have favourable views of unhealthy foods and beverages, especially in terms of convenience and enjoyment.

3. Interventions are needed to address parents' attitudes to these foods to improve children's diets.

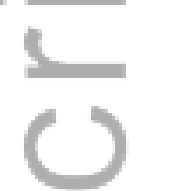

What this paper adds:

1. Factors associated with attitudes to energy-dense, nutrient-poor foods were found to be fundamentally similar to those for soft drinks.

2. Key factors influencing parents' perceptions of these products include social norms, children's requests, television viewing, and exposure to food advertising.

3. Stricter regulation of food advertising has the potential to address each of these influencing factors.

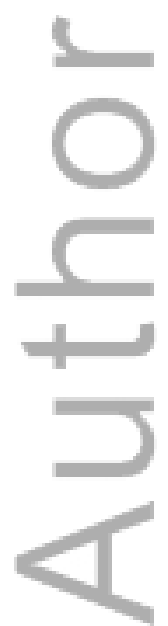




\section{Introduction}

Almost one-quarter of children and two-thirds of adults in Australia are overweight or obese ${ }^{1}$. Reflecting this situation, addressing the obesity 'epidemic' is an acknowledged national health priority ${ }^{2}$. Although child obesity rates appear to have plateaued in recent years, population levels remain high and the search continues for effective means of addressing the lifestyle behaviours associated with excess adiposity ${ }^{2}$. Diet is a particularly important intervention area, especially in terms of the consumption of energy-dense, nutrient-poor (EDNP) foods (i.e., those high in fat, sugar, and/or salt) and soft drinks (carbonated sugared beverages) $)^{3}$.

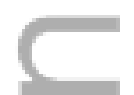

An established body of evidence demonstrates the importance of the family context in obesity interventions ${ }^{4-7}$. For example, parents' food purchase decisions impact on both their own and their children's diets through food availability in the home ${ }^{8-10}$, and parents' food modelling behaviours can have a profound and long-lasting influence on children's food preferences ${ }^{4,9}$, 11-13. In addition, parenting styles (authoritarian, authoritative, or permissive) have been associated with the quality of children's diets and weight outcomes ${ }^{14-16}$.

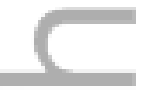

Overweight children are more likely to become overweight adults than their normal weight counterparts $^{17,18}$. This highlights the importance of addressing child obesity among both today's children and tomorrow's adults. In addition, family-level interventions have the potential to improve outcomes for both children and their parents, thereby having greater 
overall effects at a population level ${ }^{5}$. For these reasons, parents are a critical target group because of the multiple potential pathways for dietary improvement ${ }^{6,19}$. However, to be effective, interventions targeting parents need to take account of their attitudes to unhealthy foods and beverages to ensure relevant influencing factors are addressed ${ }^{4}$.

An attitude is "a summary evaluation of a psychological object captured in such attribute dimensions as good-bad, harmful-beneficial, pleasant-unpleasant, and likable-dislikable"20. Attitudes are important predictors of behaviour, but they are complex and have multiple components and antecedents. To better understand how attitudes to specific phenomena are formed, and hence how they may be modified, it is important to identify the factors influencing each attitude dimension ${ }^{21}$. In the context of food choices, primary dimensions have been found to include taste, price, convenience, and healthiness ${ }^{7,19,22-25}$. However, evidence is lacking in terms of the specific factors influencing these dimensions and how these factors may vary between different categories of food products.

The pervasive availability and marketing of 'junk food' has long been acknowledged as a contributor to rapidly rising obesity rates ${ }^{26,27}$. More recently, increasing emphasis has been placed on the specific role of soft drinks and other sugar-sweetened beverages in contributing to a positive energy balance, thereby increasing the risk of obesity ${ }^{28-30}$. High levels of consumption of soft drinks are likely to be a reflection of the substantial advertising expenditure devoted to this product category ${ }^{31,32}$. Given growing health concerns about soft drink consumption combined with high levels of intake, it is timely to assess parents' 
attitudes to this product category and how they compare to attitudes for EDNP foods to inform future health promotion efforts in this area.

Of particular interest in the present study were the factors influencing the dimensions of parents' attitudes to EDNP foods and soft drinks and whether there are variations between these two categories. Building on a previous study that assessed the relative weighting of specific attitudinal dimensions relevant to parents' perceptions of EDNP foods and soft drinks (citation to be inserted after blind review), the aim was to examine the factors associated with these dimensions to identify key areas for attention in future interventions.

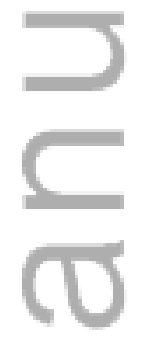

\section{Method}

To identify the factors influencing parents' attitudes to the two product categories of interest, a diverse sample of Australian parents $(n=1,302)$ was accessed via a large web panel provider (PureProfile). Recruitment criteria were gender and having at least one child in the 8 to 14 years age range. Reflecting the continuing primary role of mothers in primary child care ${ }^{4,33}$, quotas were used to achieve a sample comprised of two-thirds mothers and one-third fathers. The child age group was selected because (i) children in the concrete operational and formal operational development stages begin to engage in deductive reasoning, which can be expected to result in a heightened ability to anticipate consequences of their choices ${ }^{34}$ and (ii) children in this age range ('tweenies') have been identified as substantial influencers of family shopping decisions ${ }^{35}$. These attributes combine to make this age group of particular 
relevance for interventions designed to build lifelong good nutrition habits, and similar age ranges have been used in previous research investigating parents' nutrition-related attitudes and behaviours ${ }^{36,37}$.

The sample profile is shown in Table 1. Respondents completed an online survey that assessed their attitudes to EDNP foods and soft drinks through items relating to perceived convenience, taste, goodness, and value for money. Other items were included to obtain data relating to a range of variables identified in previous research as being relevant to children's weight status and/or parents' food choices ${ }^{38-40}$. These included parent characteristics (age, gender, education, height, weight), parent media exposure (exposure to advertising for unhealthy foods and beverages, amount of television watched on weekdays and weekends), family characteristics (family structure, number of children, age of children), perceived social norms relating to diet, and children's pestering behaviours. Prior to administration, the questionnaire was tested on 28 parents during four focus groups, with only minor wording changes required. The height and weight data were used to calculate body mass index $\left(\mathrm{BMI}^{41}\right)$. The study protocol was approved by the University of XXX Human Research Ethics Committee.

Linear regression analyses were undertaken to identify the factors associated with parents' attitudes relevant to both product categories. The categories were investigated separately and in combination. Regression analyses were accomplished in two steps. First, separate univariate regression analyses were conducted for each factor to avoid any complications due to multicollinearity. In the second step, significant univariate factors were included in a 
simultaneous multivariate regression model to determine the unique contribution of each significant factor. The assumption of no multicollinearity was satisfied in all multivariate regressions conducted, with all independent variables associated with a tolerance level above the minimum criterion of 0.20 and a variance inflation factor below the maximum criterion of 10. A p-value of <.05 was used as the significance cut-off.

=
s
Results

As reported previously, most respondents considered EDNP foods and soft drinks to be convenient and enjoyable (citation to be inserted after blind review). Overall, EDNP foods were considered to be somewhat more favourable than soft drinks, especially on the dimensions of convenience and enjoyment. The dimensions of value for money and goodness were of relatively low importance to overall attitudes for both product categories (citation to be inserted after blind review).

Variables that were found in the present study to be significant factors associated with each of the attitudinal dimensions (convenience, enjoyment, value for money, and goodness) for EDNP foods are presented in Figure 1. Enjoyment scores were higher among those parents who had more children, watched more television on weekends, reported higher levels of pestering and exposure to advertising, and perceived favourable social norms for EDNP food consumption. Convenience shared the same influencing factors as enjoyment, but with higher income also associated with higher scores. Value for money scores were higher among parents with a lower BMI who watched more television on weekdays, reported more 
pestering by their children, and lived in a two-parent family. Goodness scores were higher for parents reporting more child pestering, lower levels of education, and a two-parent family structure.

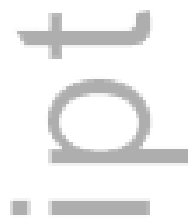

\section{Insert Figure 1 about here}

Figure 2 shows the results of multivariate regression analyses conducted for each of the dimensions for soft drinks. Convenience scores were higher among parents reporting higher levels of pestering, weekend television viewing, exposure to advertising, and perceptions of favourable social norms for soft drink consumption. Enjoyment shared the same influencing factors as convenience, with the addition of male gender, lower SES, and higher BMI.

Greater value for money was perceived by younger, less educated respondents who reported higher levels of pestering and weekend television viewing. Goodness scores were higher among male respondents, those who reported more pestering, higher levels of television viewing on weekends, a smaller number of children, and older children.

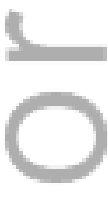

\section{Insert Figure 2 about here}

Figure 3 shows the results of multivariate regression analyses conducted for each of the dimensions of the combined overall attitude to EDNP foods and soft drinks. As was the case for the separate models, child pestering was significantly and positively associated with all four dimensions in the combined model. 


\section{Discussion}

Attitudes are an important antecedent to behaviour ${ }^{20}$, making it critical to understand relevant attitudes when developing interventions encouraging behavioural change. In the present study, parents' attitudes to EDNP foods and soft drinks were investigated independently and in combination to provide insight into the implications for healthy eating campaigns that focus on these product categories in separate or integrated campaigns. Previous research has identified convenience and enjoyment as primary motivators in parents' food choices ${ }^{4,7,10}$. Of particular interest in this study, therefore, were the factors influencing these two dimensions and how they can be addressed in interventions designed to modify parents' food and beverage provision behaviours.

In the combined model generated from the current data (Figure 3), perceived social norms, children's pestering, and reported exposure to television and food advertising were significantly associated with higher levels of enjoyment and convenience, indicating that these are especially important aspects to address in interventions targeting parents' favourable attitudes to EDNP foods and soft drinks. These four factors share a common link in that prior research has demonstrated that exposure to food advertising is associated with television viewing, nutrition-related social norms, and children's requests for unhealthy

foods ${ }^{39,42}$. A logical proposition from the results is that efforts to modify parents' attitudes to these products should include greater restrictions on food advertising. This conclusion is 
supported by reviews of the evidence relating to obesity prevention that have emphasised the role of food marketing in influencing children's diets and the need to address this pervasive force ${ }^{43,44}$.

In the Australian context, despite the existence of a system of voluntary food advertising regulation, the majority of food advertisements to which children are exposed are for unhealthy products ${ }^{31,32,45}$. The ineffectiveness of these regulations and the results of the present study support the calls for more comprehensive approaches to advertising regulation $^{46}$ A potential example lies in the way alcohol advertising is controlled in France, where only very limited information can be conveyed, such as that relating to product origin and composition ${ }^{47}$. Alcohol marketers are therefore prevented from referring to other product attributes in their promotional activities. The prevalence and severity of the health problems associated with obesity may justify a similar approach to food advertising at some point in the future to prevent food marketers aligning their products with the key attributes of enjoyment and convenience. Controlling food advertising in this way would have the added benefit of potentially modifying social norms given the demonstrated ability of such advertising to encourage people to assume that others use and endorse unhealthy foods ${ }^{39}$.

Pestering was found to be a particularly influential across both the individual and combined models. This suggests the need to ensure parents are aware of (i) the extent to which their experiences are shared by others (thereby potentially empowering them to resist the age-old argument that "everyone else is allowed to have these") and (ii) the potential for their own attitudes to these products to be influenced by their children's pestering behaviours 
(forewarned may be forearmed in this regard). However, little work has investigated the means by which parents can be assisted to manage and minimise this behaviour, and this constitutes an important area of future research ${ }^{48}$.

This study has limitations that could be addressed in future research. In the first instance, the use of a web panel provider to recruit the sample could have resulted in a non-representative group of parents participating in the study. Alternative recruitment methods may be used to generate more random samples for further work in this area. However, the sample used in the present study covered a broad range of demographic profiles, indicating that at least some of the identified relationships are likely to hold more broadly. Second, the failure of a sizeable proportion $(22 \%)$ of respondents to provide height and weight data reduced the amount of BMI information available for analysis. The lower average BMI in the present study relative to the Australian population (53\% of the sample was overweight or obese compared to $63 \%$ of the Australian population ${ }^{49}$ ) suggests that those of higher body mass were less likely to provide weight information. As a result of this discrepancy, BMI may have a greater effect on attitudes than was identified in this study. Finally, parents' attitudes to foods do not necessarily translate into their food provision behaviours ${ }^{50}$, highlighting the need for future research to assess the relationship between expressed attitudes and actual feeding practices to provide greater insight into potentially effective child obesity interventions.

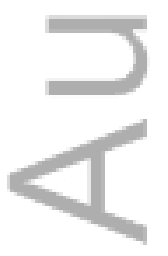




\section{References}

1 Australian Bureau of Statistics. Australian Health Survey: First Results, 2011-12. ABS, Canberra, ACT, 2012. Cat. no. 4364.0.55.001.

2 Australian National Preventive Health Agency. A Priority-Driven Research Agenda for Obesity Prevention. Commonwealth of Australia, Canberra, ACT, 2014.

3 Crino M, Sacks G, Vandevijvere S, Swinburn B, Neal B. The Influence on Population Weight Gain and Obesity of the Macronutrient Composition and Energy Density of the Food Supply. Curr Obes Rep. 2015: 1-10.

4 Adamo KB, Brett KE. Parental perceptions and childhood dietary quality. Matern Child Health J. 2014; 18: 978-995.

5 Epstein LH, Paluch RA, Roemmich JN, Beecher MD. Family-based obesity treatment, then and now: twenty-five years of pediatric obesity treatment. Health Psychol. 2007; 26: 381-391.

6 Golan M, Crow S. Parents are key players in the prevention and treatment of weight-related problems. Nutr Rev. 2004; 62: 39-50.

7 Oellingrath IM, Hersleth M, Svendsen MV. Association between parental motives for food choice and eating patterns of 12-to 13-year-old Norwegian children. Public Health Nutr. 2013; 16: $2023-2031$.

8 Birch LL, Fisher JO. Development of eating behaviors among children and adolescents. Pediatrics. 1998; 101: 539-549. 
9 Couch SC, Glanz K, Zhou C, Sallis JF, Saelens BE. Home food environment in relation to children's diet quality and weight status. J Acad Nutr Diet. 2014; 114: 1569-1579. e1561.

10 Roos E, Lehto R, Ray C. Parental family food choice motives and children's food intake. Food Qual Prefer. 2012; 24: 85-91.

11 Dickens E, Ogden J. The role of parental control and modelling in predicting a child's diet and =relationship with food after they leave home. A prospective study. Appetite. 2014; 76: 23-29.

12 Gribble LS, Falciglia G, Davis AM, Couch SC. A curriculum based on social learning theory emphasizing fruit exposure and positive parent child-feeding strategies: a pilot study. J Am Diet Assoc. 2003; 103: 100-103.

13 te Velde SJ, ChinAPaw MJ, De Bourdeaudhuij I, et al. Parents and friends both matter: simultaneous and interactive influences of parents and friends on European schoolchildren's energy balance-related behaviours-the ENERGY cross-sectional study. Int J Behav Nutr Phys Act. 2014; 11: 82-98.

14 Hughes SO, Power TG, Fisher JO, Mueller S, Nicklas TA. Revisiting a neglected construct: parenting styles in a child-feeding context. Appetite. 2005; 44: 83-92.

15 Peters J, Parletta N, Lynch J, Campbell K. A comparison of parental views of their pre-school children's ‘healthy’ versus ‘unhealthy’diets. A qualitative study. Appetite. 2014; 76: 129-136.

16 Rhee KE, Lumeng JC, Appugliese DP, Kaciroti N, Bradley RH. Parenting styles and overweight status in first grade. Pediatrics. 2006; 117: 2047-2054. $1505 S$. 
18 World Health Organisation. Population-Based Prevention Strategies for Childhood Obesity. Report of a WHO forum and technical meeting, Geneva, 15-17 December 2009, Geneva, 2010.

19 Zarnowiecki D, Sinn N, Petkov J, Dollman J. Parental nutrition knowledge and attitudes as predictors of 5-6-year-old children's healthy food knowledge. Public Health Nutr. 2012; 15: 1284-1290.

20 =Ajzen I. Nature and operation of attitudes. Annu Rev Psychol. 2001; 52: 27-58.

21 Olsen SO. Strength and conflicting valence in the measurement of food attitudes and preferences. Food Qual Prefer. 1999; 10: 483-494.

22 Lappalainen R, Kearney J, Gibney M. A pan EU survey of consumer attitudes to food, nutrition and health: an overview. Food Qual Prefer. 1998; 9: 467-478.

23 Prescott J, Young O, O'neill L, Yau N, Stevens R. Motives for food choice: a comparison of consumers from Japan, Taiwan, Malaysia and New Zealand. Food Qual Prefer. 2002; 13: 489495.

24 Russell CG, Worsley A, Liem DG. Parents' food choice motives and their associations with children's food preferences. Public Health Nutr. 2014; 18: 1018-1027.

25 Werle CO, Trendel O, Ardito G. Unhealthy food is not tastier for everybody: The "healthy= tasty" French intuition. Food Qual Prefer. 2013; 28: 116-121.

26 Cairns G, Angus K, Hastings G, Caraher M. Systematic reviews of the evidence on the nature, extent and effects of food marketing to children. A retrospective summary. Appetite. 2013; 62: $209-215$. 
27 Jeffrey DB, McLellarn RW, Fox DT. The development of children's eating habits: the role of television commercials. Health Educ Behav. 1982; 9: 78-93.

28 Grimes CA, Riddell LJ, Campbell KJ, Nowson CA. Dietary salt intake, sugar-sweetened beverage consumption, and obesity risk. Pediatrics. 2013; 131: 14-21.

29 Hu FB, Resolved: there is sufficient scientific evidence that decreasing sugar-sweetened „ beverage consumption will reduce the prevalence of obesity and obesity-related diseases. Obes Rev. 2013; 14: 606-619.

30 Vartanian LR, Schwartz MB, Brownell KD. Effects of soft drink consumption on nutrition and health: a systematic review and meta-analysis. Am J Public Health. 2007; 97: 667-675.

31 Roberts M, Pettigrew S, Chapman K, Quester P, Miller C. The advertised diet: an examination of the extent and nature of food advertising on Australian television. Health Promot J Austr. 2013; 24: 137-142.

32 Roberts M, Pettigrew S, Chapman K, Quester P, Miller C. Children's exposure to food advertising: an analysis of the effectiveness of self-regulatory codes in Australia. Nutr Diet. 2014; 71: 35-40.

33 Australian Bureau of Statistics. Australian Social Trends 2009. ABS, Canberra, ACT, 2009. Cat. no. 4102.0 .

34 Piaget J. Intellectual evolution from adolescence to adulthood. Human Develop. 1972; 15: 1-12.

35 Marshall D. Understanding children as consumers. Sage Publications Ltd, London, 2010. 
36 Rawlins E, Baker G, Maynard M, Harding S. Perceptions of healthy eating and physical activity in an ethnically diverse sample of young children and their parents: the DEAL prevention of obesity study. J Hum Nutr Diet. 2013; 26: 132-144.

37 Zarnowiecki D, Dollman J, Parletta N. Associations between predictors of children's dietary intake and socioeconomic position: a systematic review of the literature. Obes Rev. 2014; 15: $375-391$

38 Gibson LY, Byrne SM, Davis EA, Blair E, Jacoby P, Zubrick SR. The role of family and maternal factors in childhood obesity. Med J Aust. 2007; 186: 591.

39 Grier SA, Mensinger J, Huang SH, Kumanyika SK, Stettler N. Fast-food marketing and children's fast-food consumption: exploring parents' influences in an ethnically diverse sample. J Public Policy Mark. 2007; 26: 221-235.

40 Notten N, Kraaykamp G, Tolsma J. Parents, television and children's weight status: on lasting effects of parental television socialization in the Netherlands. J Child Media. 2013; 7: 235-252.

41 World Health Organisation. Obesity: Preventing and Managing the Global Epidemic. WHO Technical Report Series, Geneva, 2000.

42 Kraak V, Story M. Influence of food companies' brand mascots and entertainment companies' cartoon media characters on children's diet and health: a systematic review and research needs. Obes Rev. 2015; 16: 107-126.

43 Sacks G, Swinburn B, Lawrence M. Obesity Policy Action framework and analysis grids for a comprehensive policy approach to reducing obesity. Obes Rev. 2009; 10: 76-86. 
44 World Health Organisation. Guideline: Sugars Intake for Adults and Children. WHO, Geneva, 2015.

45 King L, Hebden L, Grunseit A, Kelly B, Chapman K. Building the case for independent monitoring of food advertising on Australian television. Public Health Nutr. 2013; 16: 22492254.

46 Smithers LG, Lynch JW, Merlin T. Industry self-regulation and TV advertising of foods to Australian children. J Paediatr Child Health. 2014; 50: 386-392.

47 World Health Organisation. European Status Report on Alcohol and Health 2014: Marketing of Alcoholic Beverages. WHO, Geneva, 2014.

48 Gram M. Buying food for the family: negotiations in parent/child supermarket shopping an observational study from Denmark and the United States. J Contemp Ethnogr. 2014; 44: 169195.

49 Australian Bureau of Statistics. Profiles of Health, Australia, 2011-13. ABS, Canberra, ACT, 2013. Cat. no. 4338.0 .

50 Goh DYT, Jacob A. Children's consumption of beverages in Singapore: knowledge, attitudes and practice. J Paediatr Child Health. 2011; 47: 465-472.

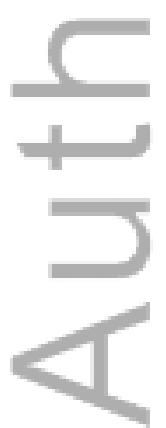


Table 1 - Sample profile $(n=1,302)$

\begin{tabular}{|c|c|c|c|}
\hline \multicolumn{2}{|c|}{ Respondent attributes } & \multirow{2}{*}{$\begin{array}{l}\% \\
67\end{array}$} & \multirow{2}{*}{$\begin{array}{c}\mathbf{n} \\
868\end{array}$} \\
\hline Gender & Female & & \\
\hline & Male & 33 & 434 \\
\hline \multirow{2}{*}{ Age } & Under 40 years & 41 & 535 \\
\hline & $40+$ years & 59 & 767 \\
\hline Weight status (BMI)* & Underweight & 3 & 30 \\
\hline \multirow{3}{*}{$=$} & Healthy weight & 44 & 440 \\
\hline & Overweight & 31 & 314 \\
\hline & Obese & 22 & 227 \\
\hline \multirow{4}{*}{ No. of children } & 1 & 29 & 378 \\
\hline & 2 & 50 & 655 \\
\hline & 3 & 18 & 230 \\
\hline & $4+$ & 3 & 39 \\
\hline \multirow{6}{*}{ Highest level of education } & Incomplete schooling & 3 & 42 \\
\hline & Year 10 & 10 & 128 \\
\hline & Year 12 & 17 & 223 \\
\hline & Technical qualification & 28 & 369 \\
\hline & Undergraduate degree & 25 & 319 \\
\hline & Postgraduate degree & 17 & 221 \\
\hline \multirow{3}{*}{ Family structure } & Single parent & 13 & 168 \\
\hline & Two parents & 79 & 1024 \\
\hline & Other & 8 & 110 \\
\hline
\end{tabular}

*missing values not reported $(\mathrm{n}=291)$

This article is protected by copyright. All rights reserved. 


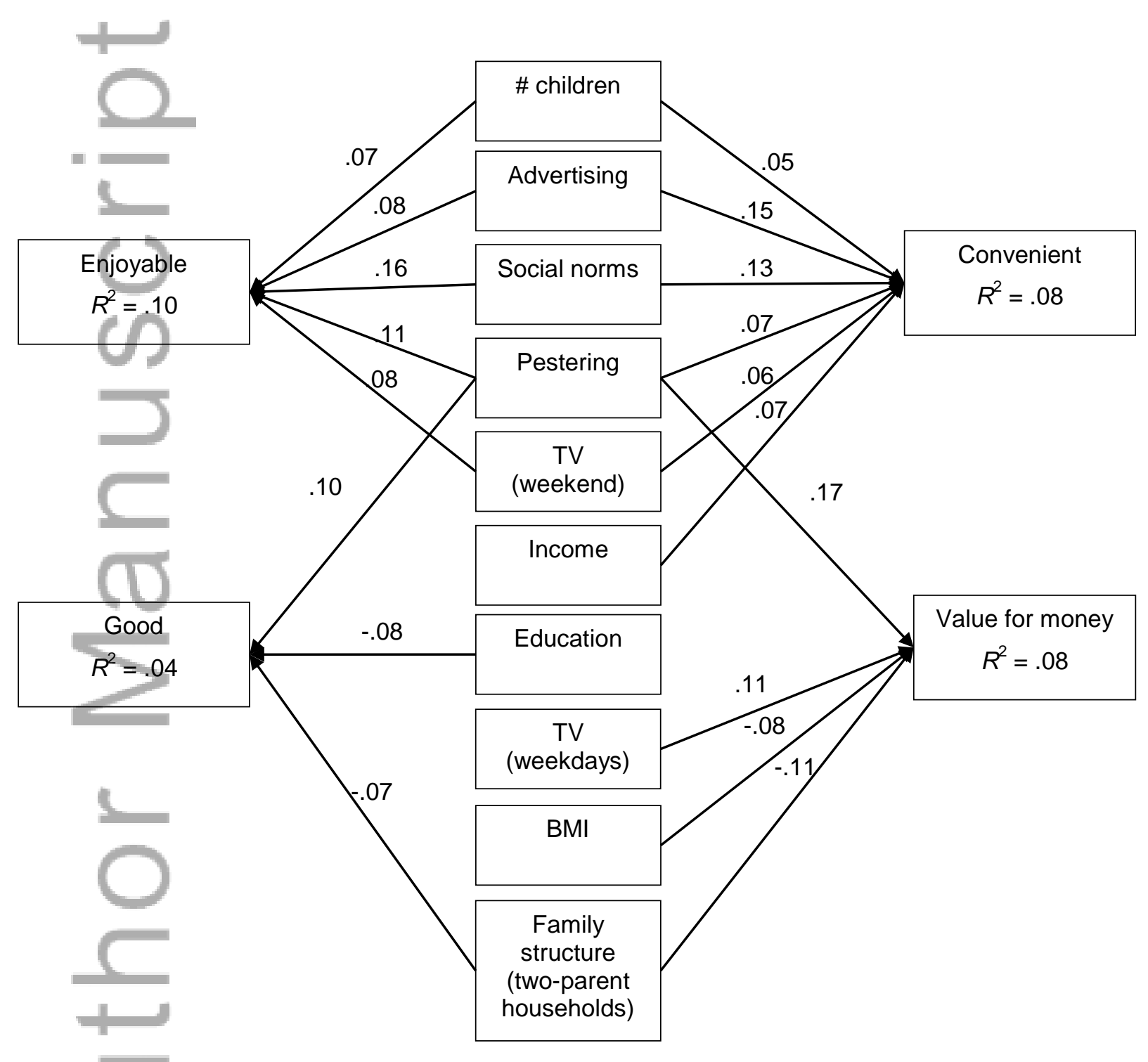

Figure 1: Factors associated with primary dimensions of parents' attitudes to EDNP foods (with standardized regression coefficients) 


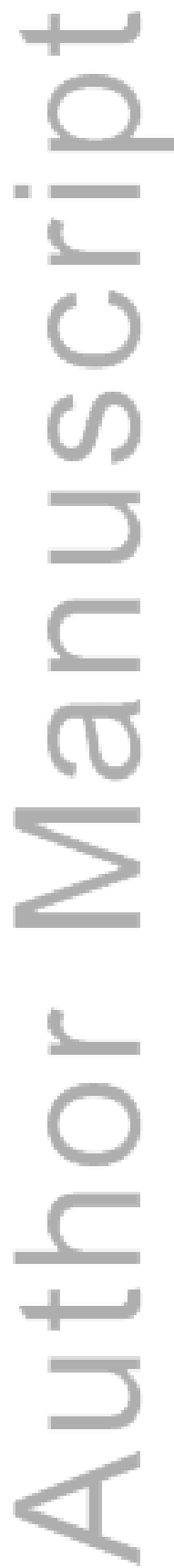

This article is protected by copyright. All rights reserved. 


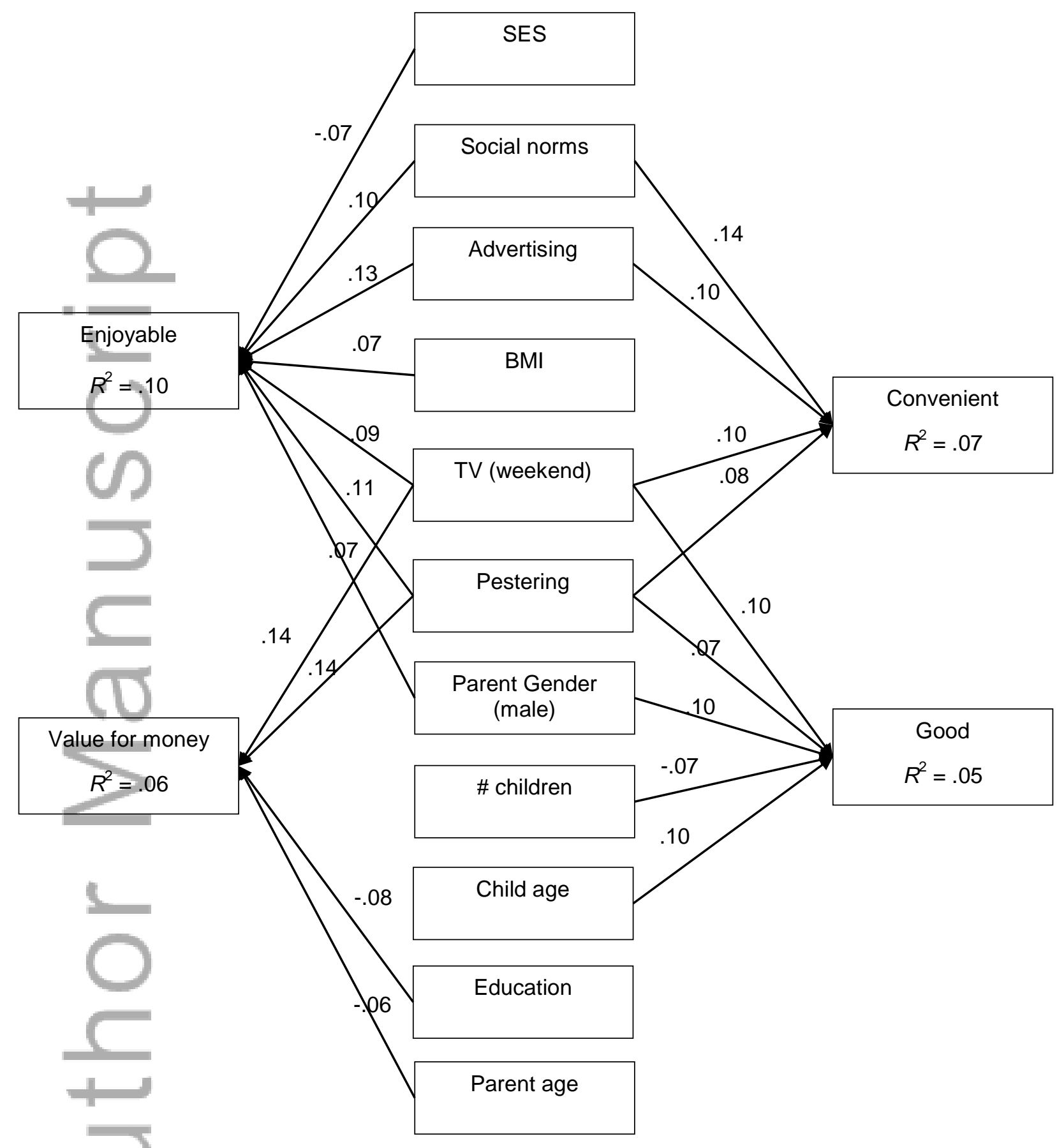

Figure 2: Factors associated with primary dimensions of parents' attitudes to soft drinks (with standardized regression coefficients) 


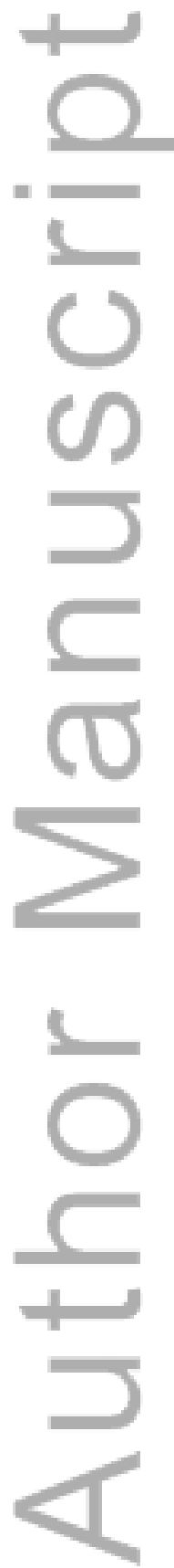

This article is protected by copyright. All rights reserved. 


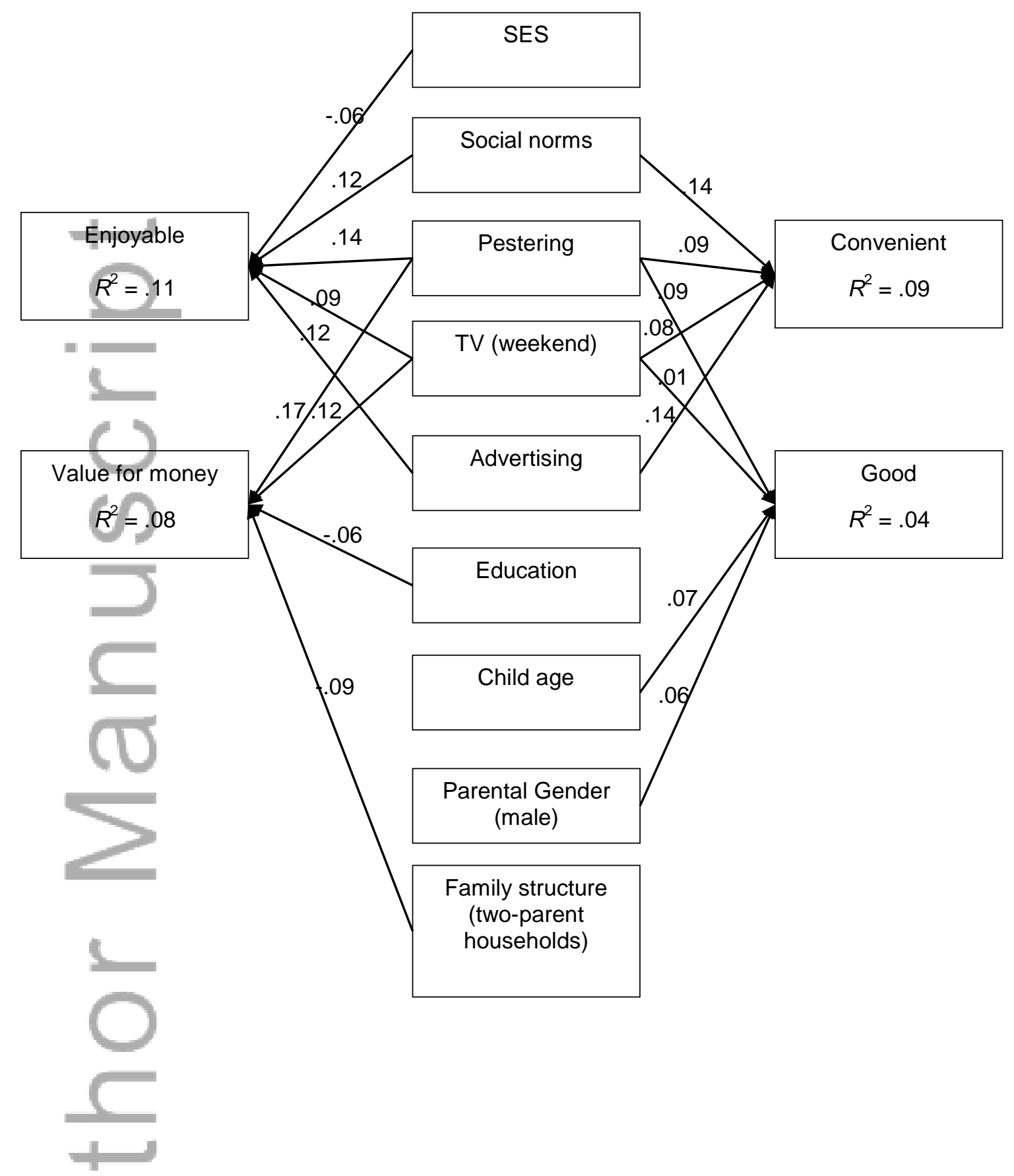

Figure 3: Factors associated with primary dimensions of parents' combined overall attitude to EDNP foods and soft drinks (with standardized regression coefficients) 


\section{University Library}

\section{- M M N E R VA A gateway to Melbourne's research publications}

Minerva Access is the Institutional Repository of The University of Melbourne

Author/s:

Pettigrew, S;Jongenelis, M;Quester, P;Chapman, K;Miller, C

Title:

Factors associated with parents' attitudes to unhealthy foods and beverages

Date:

2016-04-01

Citation:

Pettigrew, S., Jongenelis, M., Quester, P., Chapman, K. \& Miller, C. (2016). Factors associated with parents' attitudes to unhealthy foods and beverages. JOURNAL OF PAEDIATRICS AND CHILD HEALTH, 52 (4), pp.449-454. https://doi.org/10.1111/jpc.13148.

Persistent Link:

http://hdl.handle.net/11343/291118 